\title{
CrimRxiv
}

\section{The adaptable law enforcement officer: Exploring adaptability in a covert police context}

Simon Oleszkiewicz, Lynn Weiher, Erik Mac Giolla

Published on: Feb 16, 2022

DOI: $10.21428 / \mathrm{cb} 6 \mathrm{ab} 371 . \mathrm{d} 04835 \mathrm{co}$

License: Creative Commons Attribution 4.0 International License (CC-BY 4.0). 
